\title{
MARKA MENŞEI TANIMA DOĞRULUĞU KAVRAMI VE MISIR PAZARINDAKI TÜRK MARKALARI ÜZERİNE BİR ARAŞTIRMA*
}

\author{
BRAND ORIGIN RECOGNITION ACCURACY AND A RESEARCH FOR \\ TURKISH BRANDS IN THE EGYPT MARKET
}

\author{
Ahmet KOÇAK ${ }^{* *}$ iD \\ Azra BAYRAKTAR ${ }^{* *}$ iD
}

Öz

Markalı ürün ve hizmet ihracatı, ülkelerin ekonomileri için hayati öneme sahiptir. Markaların, yer aldıkları pazarlardaki bilinirliklerini ve menşei algılarını ölçmek, mikro düzeyde işletmelerin, makro düzeyde ise küresel kamuoyunun o ülke markasına dair algılarının yönetilebilmesi için, büyük önem taşımaktadır. Bu çalışmada, marka literatürü ve pazarlama uygulamalarında önemli bir yeri olan Marka Menşei kavramı araştırılmış; gelişmekte olan bir Kuzey Afrika pazarı olan Mısır'da, sekiz yüz kırk Mısırlı tüketiciye, ülkede faaliyet gösteren on iki Türk markanın menşelerini doğru tanıma testi yapılmıştır. Orijini en yüksek oranda doğru bilinen ilk üç marka, Türk markaları olan Ülker, İstikbal ve Paşabahçe olmuştur.

Anahtar Kelimeler: Marka orijini, ülke menşei, Türk markaları, Mısır pazarı

JEL Sinıflamasi: M31, M39

\section{Abstract}

Exports of branded products and services are vital for the economies of all countries. Measuring brand awareness and the perception of brand origin in the markets where brands operate is of great importance to both countries and enterprises to flourish the perceived country brand. In this study, the concept of Brand Origin, which has an essential place in brand literature and marketing applications, was investigated; Eight hundred and forty Egyptian consumers were tested to recognise the origin of the twelve Turkish brands

* Bu çalışma, Marmara Üniversitesi Sosyal Bilimler Enstitüsü Üretim Yönetimi ve Pazarlama Anabilim Dalında Prof. Dr. Azra Bayraktar danışmanlığında yürütülen ve Ahmet Koçak tarafından hazırlanan doktora tezinin bir bölümünden oluşturulmuştur.

** Arş. Gör. Dr., Bingöl Üniversitesi İİB, ahmetkocak@bingol.edu.tr

*** Prof. Dr., Marmara Üniversitesi, İşletme Fakültesi, abayraktar@marmara.edu.tr

To cite this article: Koçak, A. \& Bayraktar, A. (2019). Marka menşei tanıma doğruluğu kavramı ve Mısır pazarındaki Türk markaları üzerine bir araştırma. Journal of Research in Business, 4(2), 111-123. 
operating in the country. The first three brands whose origin is known to the greatest extent have been Turkish: Ülker, İstikbal and Paşabahçe.

Keywords: Brand origin, country-of-origin, Turkish brands, Egypt market

JEL Classification: M31, M39

\section{Giriş}

"IKEA, İsveç’in imajı için hükümetin tüm çabalarından daha fazlasını yapmaktadır. IKEA'yı ziyaret etmek, İsveç’i ziyaret etmek gibidir.” İsveç Enstitüsü eski direktörü. 2019 yllı itibariyle 49 pazarda 412 mağaza ile yer alan IKEA yaklaşık son 30 yıldır, İsveç’in ülke tutundurması için kurulan hükümet ajansının ifadesiyle, İsveç’in kültürel kavramlarını, sembollerini ve politik duruşunu, stratejik bir şekilde metalaştırmakta ve dünya geneline ihraç etmektedir (The Conversation, 2018; IKEA, 2019).

Kotler ve Gertner (2002), bir ülke markasının imajını değerlendirmenin ve rakiplerinin imajlarıyla kıyaslamanın, ülkenin pazarlama stratejisinin tasarlanmasında önemli bir adım olduğunu ifade etmektedir. Bugün ulusların markalarını yönetip ve kontrol etmeleri için birçok neden olduğu; turistlerin, fabrikaların ve şirketlerin dikkatini çekme ihtiyacının, farklı hedef gruplar için bilinçli markalaşma stratejileri gerektirdiği, ayrıca vurgulanmaktadır. Ancak, bazı markalamalar, örneğin İlanda’nın (güzel ülke imajıyla) turistleri ve (yüksek teknoloji imajıyla) yazılım uzmanlarını çekmek istediğinde bir çelişkili yaşanabilmektedir.

Kotler, Jatusripitak ve Maesincee (2005), nüfus, GSMH ve milli gelir açısından küçük bir Avrupa ülkesi olan Danimarka’nın karşılaştırmalı üstünlükler ilkesine çok iyi bir örnek olduğunu ifade etmektedir. Neredeyse hiçbir mineral kaynağı olmayan ve tarıma elverişli alanları sınırlı olan bu ülkenin, ekonomisinin temelini oluşturan pek çok ürünü ve hammaddeyi ithal etmek zorunda kaldığı fakat bu ithalatı karşılayabilmek için hem Avrupa'da hem dünyada karşılaştırmalı üstünlüğe sahip şu iki ihracat ürünü üzerinde uzmanlaştığını ileri sürmektedir: Tereyağı ve Lego. Tereyağı, büyük arazi, enerji ve hammadde gerektirmeyen sadece günlük süt uzmanlığ gerektiren bir üründür. Lego ise, üretimi zor olan fakat uzun yıllar dayanabilen, kullanışlı, üstün kaliteli, özellikle çocuklar için önemli bir oyuncaktır. Danimarka’nın bu şekilde ticaretini dengelediği, çok çeşitli kalemlerden oluşan ithalatını karşıladığı vurgulanmaktadır.

Dünya Ticaret Örgütü’nün 2001 verilerine göre 2020'de 100 milyon Çinlinin her yıl yurtdışına seyahat edeceği tahmininden hareketle Rojas-Méndez vd. (2013), gelen (inbound) turizm için yarışan ülkelerin, ülke/ulus markalarına yönelik tutumları pozitif yönde etkileyebilmek için Çinlilerin rakip destinasyonlara dair algılarını anlamaları gerektiğini önermektedir. Ayrıca, iş dünyasının globalleşmesinin birlikte, hem Çin’in yabancı yatırımcılar için çok cazip bir pazar haline geldiğini hem de büyüyen Çinli firmaların kendilerinin de diğer ülkeler için önemli yatırımcılar haline geldiğini ifade etmektedir. Çin’in yeni gerçekliğinin, Çinlilerin bir tüketici, bir turist, bir yatırımcı, bir iş ortağı vb. rollere sahip kişiler olarak ele alınarak zihinlerinde taşıdıkları ulus markası algılarının araştırılması ve anlaşılmasını önemli hale getirdiği vurgulanmaktadır. 
Türkiye ülke markası ve Türk markaları için uzun yıllardır ulusal ve uluslararası çapta çevrim içi ve çevrim dışı olarak turizm, ihracat, kültür vd. tanıtım faaliyetleri, markalaşma programları, teşvik ve destek uygulamaları sürmektedir. Fakat, Türkiye markasının temel değer önerisindeki belirsizlik ve kavram kargaşasından ötürü, ne ülke markası ülke menşeili markalardan güç alabilmektedir ne de ürün markaları ülke markalarından kendine tam bir itibar ve kredibilite sağlayabilmektedir.

Avrupa ve Amerika gibi rekabetin çok yoğun ve pazarın doygun olduğu gelişmiş ülkelerde pazar pay almanın uzun yıllar aldığı ve büyük pazarlama yatırımları gerektirdiği bir gerçektir. 1990 yılında Britanya pazarına giren Arçelik A.Ş., Beko markasıyla uzun yıllar düşük fiyat-iyi kalite stratejisiyle hareket etmiş, global pazarda \%2 pay alabilme vizyonuyla dünyanın ilk devlet destekli markalaşma programı Turquality desteği almış, küresel çapta sponsorluk anlaşmaları yapmış ve 2018'e gelindiğinde ancak birkaç kategoride pazar lideri olmayı başarabilmiştir (Financial Times, 2012; Beko PLC, 2019).

Stratejik bir ülke markalaşması için atılacak adımlardan biri, bir ülkenin işletmelerine ve markalarına kısa ve uzun vadede daha fazla marka bilinirliği, yüksek pazar payı ve pazar liderliği imkânlarını sağlayabilecek, menşe ülkeye markalı ve yüksek katma değerli daha fazla ihracat yapma şansı verebilecek, örneğin Kuzey Afrika, Orta Doğu ve Doğu Avrupa gibi gelişmekte olan bölgelerdeki ülkelere odaklanmaktır. Bu sayede ülkenin bayrak taşıyıcıllğını üstlenebilecek markalar, o ülkenin insanlarıyla daha fazla etkileşim içerisine girebilir, IKEA örneğinde olduğu gibi, insanların zihninde markanın menşei olan ülkeye de dair izler bırakabilir.

Türkiye İhracatçllar Meclisi 2019 İhracat Raporu’na göre yüksek büyüme beklentileri ile öne çıan ilk 11 ülke arasında, MENA bölgesi ve Misır yer almaktadır. Mısır, Afrika kıtasında Türkiye’nin 2019 yılı en fazla ihracat yaptığı, Türk işletmelerinin 2 milyar \$ doğrudan yatırımı bulunan bir ülkedir; Ülker (Pladis), Beko (Koç), Kordsa (Sabancı), Şişecam (Paşabahçe), Limak, Hayat Kimya, DNM (Eroğlu), Arkas gibi büyük grup işletmeler ve markalar bu pazarda uzun yıllardır yer almaktadır. İki ülke arasındaki ticaret hacmi, 2013'te Mısır'da yaşanan ve Türkiye ile siyasi ilişkilerinin kopmasına sebep olan askeri darbe öncesine kadar 5,1 milyar \$ seviyesine kadar yükselmiş, sonra düşüşe geçmiş, 2018 yılı itibariyle tekrar artarak 5,24 milyar \$ gibi rekor bir seviyeye çıkmıştır. Son 15 yılda itibariyle ticaret hacmindeki artış 40 kata ulaşmıştır (TOBB, 2019).

\section{Literatür Taraması}

\subsection{Marka Menşei Tanıma Doğruluğu (BORA)}

Ülke Menşei (COO), tüketicilerin karar alma süreçlerinde etkili olduğunu göstermekte, dışsal bir bilgi referansı olarak ürün değerlendirmelerini doğrudan veya dolaylı olarak etkili olmaktadır (Thakor, ve Kohli, 1996; Pharr, 2005; Magnusson vd., 2011; Sharma, 2011; Aktan ve Chao, 2016; Herz ve Diamantopoulos, 2017; Garrett vd., 2017;). Thakor ve Kohli (1996), artık çoğu markanın üretim yerinin etiketindeki ülke olmamasından dolayı Ülke Menşei (COO) yerine Marka Menşei (BO) kullanımının daha kapsayıcı bir kavram olduğunu ileri sürmüşlerdir. Marka Orijini’nin bir ülke olmak zorunda olmadığı veya bunun yerine bir bölge de olabileceği, COO ile BO’yu ayırt etmek 
için kullanılacak bir yol olarak COO’in ürünler için BO'in ise markalar için kullanıldığı, ayrıca ifade edilmektedir.

Alanda yapılan araştırmalar, marka menşeinin ülke menşeine benzer şekilde tüketicilerin kalite algılarını, marka ile ilgili tutumlarını ve satın alma niyetlerini etkilediğini ve stereotipler meydana getirdiği açıklamaktadır (Zhuang vd, 2008). Ülke menşeinin, sadece ürün değerlendirme sürecini etkilemekle sınırlı kalarak satın alma niyeti üzerinde doğrudan hiçbir etkisi bulunmadığı da ileri sürülmektedir (Usunier, 2006). Bunların yanında, satın alma karar sürecine olan etkisi devamlı sorgulanmaktadır (Samiee vd. 2005, 2011; Balabanis ve Diamantopoulos, 2008, 2011).

Marka menşei, ülke menşeinden birkaç şekilde ayrılmaktadır. Birincisi; Marka Orijini, önemli olanın markanın asıl lokasyonu değil algılanan lokasyonu olduğunun, esasen vurgulananın bu olduğunun altı çizilmektedir. Bu algılanan menşei çağrışımı, reklam ile veya marka adıyla eşleşen dil ile yaratılabilmektedir (Thakor ve Lavack, 2003).

Marka Orijini kavramı, genel bir ifadeyle, bir markanın hedef kitlesi tarafından algılanan o markanın ait olduğu yer, bölge veya ülke olarak tanımlanabilir. Menşei işaretlerinin marka imajına entegrasyonunun muhtemel en yaygın yolu, ilgili ülkenin genel kabul görmüş bazı doğal kaynaklarından veya uzmanlığından, söz konusu markanın fayda elde edebileceği bu çağrışımlar üzerinden, bir markaya bir milliyet/uyruk sağlama girişimidir (Thakor ve Kohli, 1996).

Bu bağlamda, pazarlama akademisyenleri ve uygulamacıları, tüketicilerin herhangi bir markanın asıl kökenini / menşeini tanıyabilme yeteneklerini sorgulamaktadırlar. Bu konuyu sistematize etmek amacıyla Samiee vd. (2005) tarafından, tüketicilerin markaların orijini ile ilgili kısıtlı bilgilerini test edebilmek ve bir grup marka örneğinin menşeilerini tanımayabilme kabiliyetini değerlendirebilmek için, BORA ölçüm sistemi tasarlanıp literatüre kazandırılmış, sonrasında birçok çalışmada kullanılmıştır (Magnusson vd, 2011; Balabanis ve Diamantopoulos, 2008).

Marka isimleri fonetik açıdan her zaman farklı yapıda yer alabilmektedir. Ürününü parfümleriyle meşhur Fransa menşeli göstermek isteyen bir parfüm üreticisi, ürününe, Fransızca bir marka ismi vererek marka menşei algısını Fransa olarak inşa etmek isteyebilir. Usunier (2011)'e göre bir markanın uzun vadede veya halihazırda uluslararasılaşması/ globalleşmesi için kendisine AngloAmerikan gözüken marka isimlerini adapte ettikleri ifade edilmektedirler. Zhuang vd. (2008)'a göre bu yaklaşım, örneğin Çin menşeili yerel bir giyim markası Jasonwood gibi, tüketicilerin kafasında kargaşaya sebep olsa da tercih edilebilmektedir. Türk işletmeleri de de aynı şekilde, Pastavilla, Bingo, Casper, Collezione, English Home, Gratis, Greyder, Lera FrescaMadame Coco, Mintax, Molfix, Kinetix, Sarelle vb. gibi İngilizce, İtalyanca vd. dillerin karakterlerine, telaffuzuna sahip marka adlarıyla, yerel ve uluslararası pazarlarda yer almaktadırlar.

Abdellah-Kilani ve Zorai (2019)'nin çalışmasından hareketle, marka menşeini doğru tanıma, tüketicilerin bir marka hakkındaki gerçek bilgilerini dört tür farkındalık açısından ortaya çıkarır: Ülke menşeinin baskınlığı, marka bilinirliği, marka orijini farkındalığı ve marka orijini tanıma doğruluğu. Marka orijini literatürüne dair eleştirileri, Abdellah-Kilani ve Zorai (2019), araştırmacıların günümüz 
tüketicilerinin marka menşeine (BO) artık daha az önem vermeleri üzerine tartıştıklarını şu dört gerekçeyle sıralamaktadır:

1. Martin ve Cerviño (2011)'ya göre, küresel ekonomide çoğu çok uluslu şirketin ürünlerini birden fazla ve farklı lokasyonlardan temin edip üretmeleri ve katma değer zincirlerini ulusal sınırların ötesine taşımaları ve son 20 yılda birleşme ve devralmaların birçok sektörü yeniden yapılandırması, bunların sonucunda farklı ülkelerde tasarlanmış, montajlanmış ve üretilmiş melez ürünlerin çoğalması. (Örnek: Amerika menşeili Apple markasının tasarımını Kaliforniya’da montajını Çin'de yaptığı iPhone modeli; Almanya menşeili Mercedes-Benz’in kendi ülkesinde tasarlayıp Macaristan'da üretim ve montajını yaptı̆̆ Mercedes-Benz CLA modeli)

2. Usunier (2011)'in ileri sürdüğü, bir markanın uzun vadede veya mevcutta uluslararasılaşması/ globalleşebilmesi için Anglo-Amerikan gözüken isimleri kendine adapte etmesi nedeniyle yaşanan standardizasyonun tüketicilerin ulusal kimlik algılarını etkilemiş olabileceği (Örnek: Starbucks, McDonalds)

3. Zhuang vd. (2008)'in ifade ettiği, şirketlerin tüketicilerin kafasında kargaşaya neden olabilecek global marka isimleri tercih etmeleri (Örnek: Çin menşeili yerel bir giyim markası Jasonwood; Türk menşeili Colin’s gibi)

4. Majid (2017)'ün savunduğu, marka kimliği baskınlığının ülke menşei işaretine dair herhangi bir ilgiyi geçersiz kılması (Örnek: Samsung telefon kullanıcılarının telefonunun Güney Kore menşeili olmasından ziyade Samsung ürünü olmasına güvenmesi)

Bunlara rağmen BORA konusu, Abdellah-Kilani ve Zorai (2019)'a göre, beş temel noktada eleştirilmektedir;

1. BORA puanının yapay olarak şişirilmesine sebep olabilecek, tanınmış büyük markalara (global markalara) odaklanan markalar örneği (Usunier, 2011);

2. On ürün kategorisinin, BORA skorunu saptırabilecek farklı farklı müşteri ilgilenimi ve pazarlama uygulamaları seviyelerine dahil edilmesi (Balabanis ve Diamantopoulos, 2008);

3. Testin, $\mathrm{ABD}$ şartlarında, yalnızca gelişmiş ülkelerde bulunan markalarla yapılmış olması (Samiee vd., 2005);

4. Usunier (2011)'e göre, modelin araştırma bulgularını çarpıtabilecek bir "zoraki çağrışım” üzerine kurulmuş olması, BORA’nın katılımcıların iyi bildiği varsayılan 84 marka örneği kullanılarak ölçülmesi;

5. Samiee vd. (2005) tarafından yapılan araştırmada, katılımcılara, bir mağaza ortamında bilgi sağlayıcılarca desteklenen pasif tüketiciler muamelesi yapılması; marka adı, logo vb. gibi hafızaya dayalı tercihlerde bilgi eksikliği yaşanabilecek durumlar; ürün kategorisi hakkında bilgi sahibi olanların veya öyle oldukları varsayılan tüketicilerin durumları eleştirilmektedir. Örneğin; 
perakende ortamının dışında veya bir internet aramasıyla kendi hafızalarındaki markaları spontane olarak hatırlama durumları göz ardı edilmektedir.

BORA literatüründe tüketici karakteristikleri, bir markanın kökeninin tanınması performansını büyük ölçüde etkileyen bir faktör olarak kabul edilmektedir. Marka orijini ile ilgili bazı araştırmalara göre, yüksek eğitim seviyesine sahip (Paswan ve Sharma, 2004) ve sosyoekonomik durumu yüksek (Samiee vd, 2005; Paswan ve Sharma, 2004) olan bireyler, Marka Menşei tanımada daha iyi performans gösterirken, diğer araştırmalarda (Balabanis ve Diamantopoulos, 2008), eğitim ve gelirin BORA skorları üzerinde önemli bir etkisi bulunamamıştır. Eğitim seviyesi ve geliri düşük olan tüketicilerin yabancı menşeili markaları tanımak ve satın almak için daha az fırsata sahip olmaları varsayımından dolayı, BORA skoru ile korelasyonun yabancı markalar için yerel markalardan daha güçlü olmasını beklenmektedir (Abdellah-Kilani ve Zorai, 2019).

\section{Araştırmanın Amacı ve Metodolojisi}

$\mathrm{Bu}$ çalışmada, marka menşei konusu farklı bir açıdan, yardımsız olarak marka kökenini tanıma seviyesinin test edilmesi amaçlanmıştır. Google Forms üzerinden Arapça hazırlanan soru formu, sosyal medya üzerinden dağıtılmıştır. Cevap seçeneklerinde 7 farklı ülke seçeneği, Almanya, Japonya, Türkiye, Güney Kore, İspanya, İtalya, Fransa, ile birlikte ‘Bilmiyorum’ ve 'Hiçbiri’ seçenekleri yer almıştır.

\subsection{Araştırma Ülkesinin Seçimi}

American Enterprise Institute'un 'Beyond 2030:Economic Growth in the MENA' raporuna göre, Misir, ekonomisinin gelişmekte olan ekonomilere daha fazla entegre olduğu, bunun sadece artan ticaretten değil, devlet kaynaklı kalkınma programları ortaklıklarından, yardımlar ve ekonomik devletçilikten kaynaklandığı; ülkenin çekici bir destinasyon olmasından bağımsız olarak 100 milyonluk nüfusuyla büyük bir tüketici kitlesine sahip olmasından ötürü, doğrudan yabancı yatırımlar (FDI) için popüler bir ülke olduğu ifade edilmektedir (AEI, 2019).

Hem Afrika hem Arap liginde yer alan Mısır, 2017 itibariyle 256 Milyar \$ gayrisafi yurtiçi hasıla ve 2,412 \$ kişi başı GSYİH ekonomik refah ile coğrafyasındaki ülkelerden biraz geride olmasına rağmen, Afrika kıtasında ve Arap coğrafyasında ekonomi, kültür ve siyasi konularda önemli bir aktördür. Süveyş Kanalı sayesinde hem iki kıtayı hem de iki denizi birbirine bağlayan ülke, Arap ülkelerinin en fazla nüfusa sahip olan birinci, Afrika kıtasının ise üçüncü kalabalık, nüfus büyüklüğüne göre dünyanın en kalabalık 14.üncü ülkesidir. MENA bölgesinde Misır’n sahip olduğu bu profil ve potansiyel, ülkeye ayrı bir özellik katmakta, işletmelerin Mısır’ kıtaya giriş ve yayılma noktası olarak görmesini sağlamaktadır. Ülkenin 100 milyon nüfusunun \%60’ı 30 yaş altında, \%40’1 10-29 yaş arasında yer alan ülkede medyan yaş 23,9 ve beklenen yaşam süresi ise 73 yıldır.

Türkiye’nin Mısıra ihracatı, 2018 yllında 3,05 milyar \$ ve 2019'un ilk dört ayında ise 1,052 milyar \$ olarak gerçekleşmiş, Mısır Türkiye’nin ihracatında 15. ülke olmuştur. 2019 itibariyle Türkiyennin 
genel ihracat katma değeri kg başına 1,32 \$ - 1,37 \$ arasında gerçekleşirken (Sabah, 2019), Mısıra 4437 Türk firmasıyla gerçekleștirilen ihracatın kg başına ihracat değeri 2017'de 0,9\$ seviyesinde gerçekleşmiştir (TİM Mısır Ülke Bilgi Notu, 2018).

Türk işletmesi Hayat Kimyảnın Afrika kıtasında Molfix markasıyla 15 yılda Nijerya, Cezayir ve Kamerun'da pazar lideri, Mısır ve Fas'ta ise pazar ikincisi olması; 2015’te giriş yaptığ Nijeryada iki yılda \%55 gibi güçlü bir pazar payıyla lider olması, markanın operasyonlarını nüfusunun \%7,3’ü bebeklerden oluşan Kenyàya genişletmeleri (Capital, 2019; Perakende.org, 2019), MENA bölgesinden başlamak üzere Afrika kıtasının neden dünya ekonomisi açısından önemli bir odak olduğunun açık işaretlerindendir.

Türkiye’nin yıldız ve rekabet gücünün yüksek olduğu hazır giyim sektörünün pazar lideri Lcwaikiki’nin Fas'ta 29, Misir'da 20, Tunus'ta 6, Cezayir'de 5 mağazayla (LCWaikiki, 2019); DeFactơnun Fas'ta 20152019 arası 4 yıllık performansta 23 mağazaya ulaşması ve pazarda liderliğe oynaması da (Perakende. org, 2019), bu araştırmanın bu bölge ve ülkede uygulanmasının ve sonuçlarının iş dünyası açısından anlamlı olduğunu göstermektedir. Mısır'da 300 civarı Türk şirketi faaliyet göstermekte ve ülkenin 1,2 milyar \$ olan tekstil ihracatının \%30’unu 75 bin istihdam ve iç pazarda yaklaşık 6 milyar \$ ticaret hacmine ulaşarak gerçekleştirmektedir (Ekonomist, 2017). 2019'da Türk işletmelerine özel kurulacak 1 milyon km2'lik endüstri bölgesi projesi (Dünya, 2018), Türk işletmelerinin ve markalarının mevcut durumu, gelecekleri açısından önemli bir gelişmedir.

\subsection{Markaların Belirlenmesi}

Araştırmanın amacına yönelik olarak, halihazırda Mısır pazarında yaygın dağıtıma sahip hem İngilizce hem de Türkçe karakterlere sahip Ülker, Molfix, İstikbal, Sarar, Espresso Lab, Paşabahçe, Pegasus vd. gibi markaların listede yer almasına dikkat edilmiştir. Araştırmada yer alan 12 Türk markası, ünlü cadde ve alışveriş merkezlerinde mağazası bulunan Türk markalarından ve TürkiyeMısır arasında yatırım danışmanlığı yapan uzmanların görüşlerinden hareketle belirlenmiştir. Ayrıca ülkede faaliyet gösteren global markaların menşelerinin katılımcılarca ne derece doğru bilindiğinin test edilmesi için 5 tane de global marka bu listede yer almıştır. Bu beş marka, Toyota, Zara, Gap, Starbucks ve Samsung olarak uzman görüşünden yararlanarak kararlaştırılmıştır. Cevaplayıcıların marka menşelerine verdikleri cevapların tutarlılığını ve doğruluğunu kontrol etmek amaçlanmıştır. 2013 sonrası ülkeden çıkan Kiğılı vd.; Türk Hava Yolları gibi isminde Türkiye menşeili olduğu belli olan bir marka listelenmemiştir. Yapılan ön araştırmada, BORA testi için Samiee vd. (2005)'in oluşturduğu 84 marka içeren bir marka örneği, Mısır pazarında bu kadar yüksek sayıda Türk markası yer almadığından ve araştırmanın bir amacının özellikle Türk markalarının bilinirlik oranını ölçmek olduğundan 17 ile sınırlı kalmış, fakat orijinal çalışmadaki gibi 10 kategori sağlanmaya çalışılmıştır. 
Tablo 1: Araştırma Kapsamında Menşeleri Sorulan Türk Markaları

\begin{tabular}{|c|c|c|c|}
\hline \multicolumn{2}{|c|}{ Markalar } & Kategori & \multirow[b]{2}{*}{ Çevrimiçi kanalda ve mağazalarda yer almaktadır. } \\
\hline 1 & Beko & $\begin{array}{l}\text { Tüketici elektroniği, beyaz } \\
\text { eşya }\end{array}$ & \\
\hline 2 & Bim & Perakende & 2018'de açtığ 35 mağaza ile Mısır genelinde 300 mağazaya sahiptir. \\
\hline 3 & DeFacto & Hazır giyim, moda & $\begin{array}{l}\text { 2013’te açtı̆̆ ilk mağazanın ardından } 2017 \text { sonu itibariyle Mısır'da } 9 \\
\text { mağazaya sahiptir. }\end{array}$ \\
\hline 4 & Espresso Lab & Kahve zinciri & $\begin{array}{l}\text { Sütiş grubundan olan marka, mevcut } 2 \text { şube ile şubeleşmeye devam } \\
\text { etmektedir. }\end{array}$ \\
\hline 5 & İstikbal & Mobilya & 20 yıl önce girdiği pazarda 4 mağaza ile faaliyet göstermektedir. \\
\hline 6 & Koton & Hazır giyim, moda & AVM'lerde ve e-ticaret sitelerinde tüketiciyle buluşmaktadır. \\
\hline 7 & Lcwaikiki & Hazır giyim, moda & 20 mağaza ve e-ticaretle faaliyet göstermektedir. \\
\hline 8 & Molfix & FMCG, anne/bebek & $\begin{array}{l}\text { Pazarda ikinci olan marka, yoğun dağııımla, perakende noktaları, } \\
\text { e-ticaret ve Facebook Store üzerinden satılmaktadır. }\end{array}$ \\
\hline 9 & Paşabahçe & Cam eşya & $\begin{array}{l}\text { Yurtdışındaki } 3 \text { üretim tesisinden biri Mısır'da bulunan marka, } \\
\text { ülkedeki temsilciliğiyle faaliyet göstermektedir. }\end{array}$ \\
\hline 10 & Pegasus & Havayolu & $\begin{array}{l}\text { Turistik Hurgada ve Şarm el Şeyh şehirlerine İstanbul'dan direkt uçuş, } \\
\text { Kahire'ye Nile Air ile Kahire'ye ortak uçuş yapmaktadır. }\end{array}$ \\
\hline 11 & Sarar & Hazır giyim, moda & Kahire’de 5, İskenderiye’de 1 mağazayla faaliyet göstermektedir. \\
\hline 12 & Ülker & FMCG & $\begin{array}{l}44 \text { bin ton/yıl kapasite sahip marka, } \% 16,3 \text { ile pazarda ikincidir. \%18,1 } \\
\text { paya sahip rakibiyle arasını kapatmayı hedeflemektedir. }\end{array}$ \\
\hline
\end{tabular}

\section{Bulgular}

\subsection{Demografik Bulgular}

Araştırmada 840 Mısırlı tüketiciden toplanan verilere, frekans analizi uygulanmıştır. Katılımcıların \%23’ü (190 katılımc1) daha önce Türkiye'yi ziyaret etmiş, \%77’si (650 katılımc1) daha önce Türkiye’ye hiç gelmemiştir. Diğer tüm demografik veriler detaylarıyla aşağıdaki tabloda yer almaktadır.

Tablo 2: Araştırmanın Demografik Verilerinin Sonuçları

\begin{tabular}{|c|c|c|c|c|c|}
\hline \multicolumn{3}{|l|}{ Cinsiyet } & \multicolumn{3}{|l|}{ Çalışma Durumu } \\
\hline & Frekans & $(\%)$ & & Frekans & $(\%)$ \\
\hline Kadın & 535 & 63,7 & Çalışmıyor, aktif iş arıyor & 189 & 22,5 \\
\hline Erkek & 305 & 36,3 & Tam zamanlı & 276 & 32,9 \\
\hline Toplam & 840 & $\% 100$ & Yarı zamanlı & 54 & 6,4 \\
\hline \multicolumn{3}{|c|}{ Medeni Durum } & Kendi İşi & 130 & 15,5 \\
\hline Bekar & 292 & 34,8 & Öğrenci & 149 & 17,7 \\
\hline Evli & 532 & 63,3 & Emekli & 16 & 1,9 \\
\hline Diğer & 16 & 1,9 & Ev Hanımı & 26 & 3,1 \\
\hline Toplam & 840 & $\% 100$ & Toplam & 840 & $\% 100$ \\
\hline \multicolumn{3}{|l|}{ Yaş } & \multicolumn{3}{|l|}{ Bölge/Şehir } \\
\hline $18-24$ & 203 & 24,2 & Kahire & 379 & 45,1 \\
\hline $25-34$ & 380 & 45,2 & İskenderiye & 133 & 15,8 \\
\hline $35-44$ & 174 & 20,7 & Delta & 238 & 28,3 \\
\hline $45-54$ & 61 & 7,3 & Güney Mısır - Said Bölgesi & 58 & 6,9 \\
\hline
\end{tabular}




\begin{tabular}{|c|c|c|c|c|c|}
\hline 55 ve üstü & 22 & 2,6 & Süveyș & 21 & 2,5 \\
\hline Toplam & 840 & $\% 100$ & Diğer & 11 & 1,4 \\
\hline \multicolumn{3}{|l|}{ Mezuniyet } & Toplam & 840 & $\% 100$ \\
\hline İlköğretim & 2 & 0,2 & \multicolumn{3}{|l|}{ Gelir Durumu } \\
\hline Lise & 158 & 18,8 & $0-1200$ EGP & 235 & 28,0 \\
\hline Lisans & 546 & 65,0 & $1201-2500$ EGP & 130 & 15,5 \\
\hline Yüksekokul & 3 & 0,4 & $2501-5000$ EGP & 146 & 17,4 \\
\hline Y. Lisans & 106 & 12,6 & 5001 - 8000 EGP & 111 & 13,2 \\
\hline Doktora & 25 & 3,0 & 8001 EGP ve üstü & 218 & 26,0 \\
\hline Toplam & 840 & $\% 100$ & Toplam & 840 & $\% 100$ \\
\hline
\end{tabular}

\subsection{BORA Skoru Sonuçları}

Araştırmanın sonucunda, 2019 Mayıs itibariyle 101 milyon nüfusa sahip Mısır’a, FMCG pazarında yer alan Ülker'in, en yüksek oranda doğru tahminle katılımcıların \%85’i tarafından, Türkiye menşeili olduğu bilinmiştir. İstikbal \%82 ile ikinci, Paşabahçe \%77 ile üçüncü sırada, marka menşeileri doğru olarak bilinen markalar olmuşlardır. Katılımcılara yöneltilen markalar arasında en düşük oranda marka menşei doğru bilinen ise, \%6 ile Espresso Lab olmuştur. Global markaların menşelerinin doğru bilinme oranları ise sırasıyla; Toyota (Japonya) \%77, Samsung (Güney Kore) \%57, Starbucks (ABD) \%47, Gap (ABD) \%20, Zara (İspanya) \%18) olarak çıkmıştır.

Tablo 3: Markaların BORA Skorları

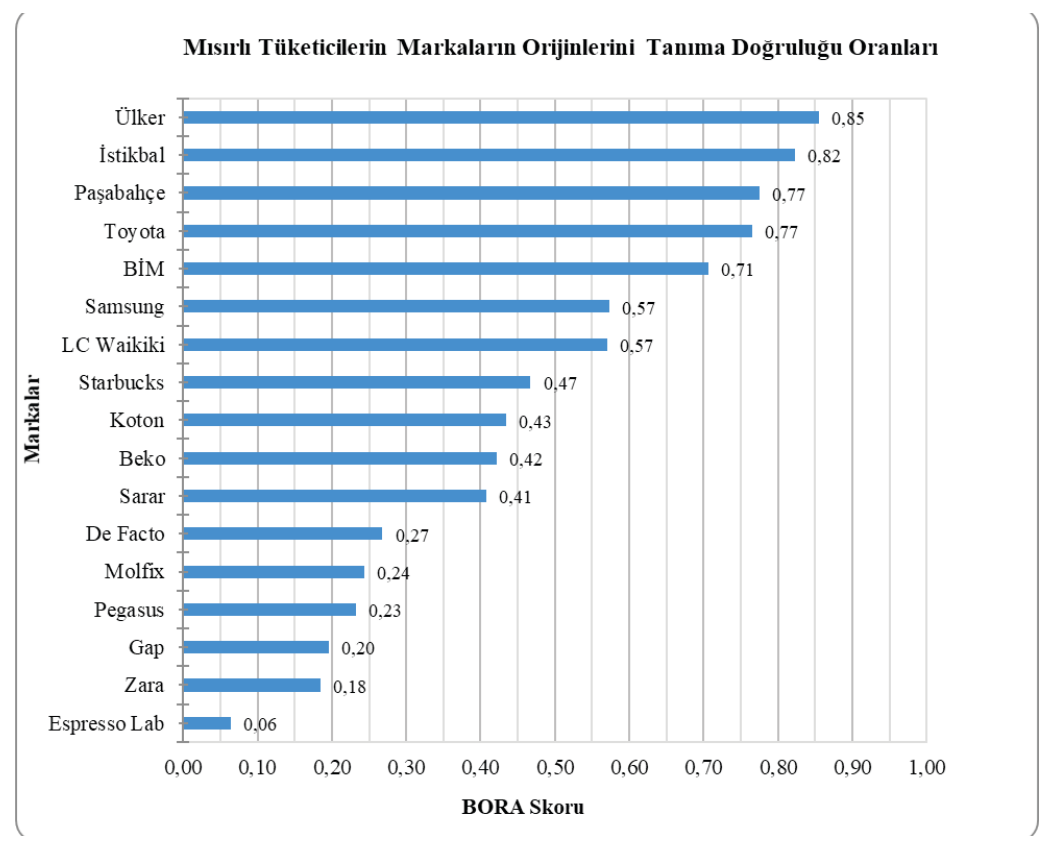

Brand Finance 2019 sonuçlarına göre Toyota, Japonya’nın en değerli, dünyada ise Mercedes-Benz'den sonra ikinci en değerli otomotiv markası olmasına rağmen araştırmada 4. En yüksek BORA skoru alan marka olmuştur. Mısır'da otomotiv pazarında Toyota’nın \%7,3 ile 5. Sırada yer alması, Güney 
Kore’nin gelişmiş teknoloji ürünleri ve otomotiv markalarının zihinlerde karışıklığa sebep olmuş olması mümkündür.

Mısır'da genel halkın gelir seviyesinden ötürü Zara ve Gap gibi nispeten yüksek fiyatlı tekstil ürünlerine olan ilginin, dolayısıyla da menşeleri doğru tanımaları normaldir.

\section{Sonuç}

\subsection{Tartışma ve Öneriler}

840 örneklemli bu araştırmada, Mısırlı tüketicilerin orijinini en yüksek oranda doğru bildikleri ilk beş markanın dördünün Türk markası Ülker, İstikbal, Paşabahçe ve BİM olması, Mısır'da ve Mısır pazarını takip eden bölge ülkelerinde Türkiye’ye, Türk ürünlerine ve Türk markalarına dair daha etkili bir pazarlama iletişimi yapılabileceğini akla getirmektedir.

Mısır pazarında mevcut ve pazara yeni girecek bir Türkiye menşeli marka veya yeni bir ürün için, reklam maliyeti ve marka bilinirliği noktasında bir kaldıraç etkisi yaratmak amacıyla ortak pazarlama iletişimleri de düşünülebilir. Dünya çağında ün kazanan ve popülerliğini artıran Türk dizileri Mısırlılar tarafından da izlenmektedir. Bu yapımlarda oynayan ünlülerin Mısır'da faaliyet gösteren Türk markalarının pazarlama iletişimlerinde yer alması, reklamlarda Mısırlılarca sevilen Türk sanatçıların ya da modellerin kullanılması, dizilerde Türk markalarının ve/veya ürünlerin senaryoya yerleştirilmesi düşünülebilir.

2018 Super Bowl'da PepsiCo şirketinin markalarından olan Doritos (cips) ve Mountain Dew (sodalı içecek), tüketicilere aynı reklamda, Game of Thrones aktörlerinden Peter Dinklage, THY’nin reklam yüzü de olmuş Morgan Freeman ve repçi Missy Elliott ile tanıtılmıştı (Business Insider, 2018). Bu yüksek tanınma oranı, reklam dünyasında başarması zor ama dahice görülen 'bir reklam iki ürün' konseptinin uygulanmasına imkân verebilir.

Türk işletmeleri, markaları ve ürünleri ile Mısır ekonomisinde önemli bir yükü taşıdığını görülmesine rağmen, 2013 yılında Mısır'da yaşanan askeri darbe sonrasında Türkiye ile Mısır arasında süregiden siyasi problem, Mısır vatandaşlarının zaman zaman Türk ürünlerini boykot etme çağrıları yapmalarına kadar uzanmıştır. Facebook üzerinden Türk markalarının ve mağazalarının paylaşıldığı mesajın 12,000 beğeni aldığı belirtilmektedir (The Arab Weekly, 2018). Diğer yandan ihracat rakamları ve iki ülke arasında sessizce sürdürülen ekonomik ilişkiler, sürekli ve etkili bir boykotun Mısırlı tüketicilerde karşılık bulmadığına, Türkiye menşeili ve Türk markalı ürünler için pazarda büyüme potansiyelinin devam ettiğine bir işaret olarak görülebilir. Ayrıca, Türkiye’nin Mısır’a yaptı̆̆ 1 ihracatın kg başı değeri, yoğunlukla ara mal, yarı mamul ve hammadde satmasının etkisi görülmektedir. Türkiye’nin daha fazla ihracat geliri elde etmek için, Mısır’a kg başı değeri yüksek markalı ihracat yapması gerekmektedir. 


\subsection{Gelecekteki Araştırmalar}

Katılımcıların Türkçe bilip bilmedikleri, Türkçeye ve Türkçe karakterlere aşinalıkları; yabancı dilbilgisi ile marka orijinleri arasındaki ilişki, marka menşeini doğru bildikleri ürünleri ne sıklıkla tükettikleri; bu markaların pazarlama iletişimlerine ne yoğunlukta maruz kaldıkları araştırılabilir. Ayrıca, reklamda ünlü kullanımının bu pazarda Türk ürünlerinin hızlı bir şekilde marka bilinirliğini yükseltmelerindeki rolü de ölçülebilir. Türk dizileri sayesinde tanıyıp takip ettikleri ünlülerin marka yüzü oldukları markaları ne derece tükettikleri ve Türkiye’ye karşı tutumlarıyla olan ilişkisi, takip ettikleri Türk TV dizileri sayesinde Türk ürünlerine olan ilginin artıp artmadığı da araştırılabilir. Marka adında İngilizce karakter içeren Molfix bebek bezi, pazarda ikinci konumdadır ve yapılan ön çalışmada premium bir ürün olarak görülmektedir ve marka menşeinin doğru tanınma oranı ise \%24 oranındadır. Bu, marka yöneticileri için önemli bir konudur. Molfix gibi İngilizce karakter içeren, nispeten 'Batılı' ya da 'yabancı' gözüken markanın esasen nasıl algılandığı; sektör ve kategorilere göre Türkçe bir marka isim kullanılıp kullanılmamasının ne tür avantaj ve dezavantajlar doğuracağı araştırılmalıdır.

\section{Kaynakça}

Abdellah-Kilani, F., \& Zorai, R. (2019), "Brand Origin Recall Accuracy (BORECA): a new measure of brand origin salience", International Marketing Review, 36(3), 464-482.

Aktan, M., \& Chao, P. W. (2016), "Impact of Country Personality on Attitude Toward Foreign Products : Selfcongruity as a Mediator", Atlantic Marketing Journal, 5(1), 155-171

Balabanis, G. and Diamantopoulos, A. (2008), "Brand origin identification by consumers: a classification perspective", Journal of International Marketing, 16(1), 39-71.

Balabanis, G. and Diamantopoulos, A. (2011), "Gains and losses from the misperception of brand origin: the role of brand strength and country-of-origin image”, Journal of International Marketing, 19(2), 95-116.

Garrett, T.C., Lee, S. and Chu, K. (2017), “A store brand's country-of-origin or store image: what matters to consumers?", International Marketing Review, 34(2), 272-292.

Herz, M.F. and Diamantopoulos, A. (2017), “I use it but will tell you that I don't: consumers' country-of-origin cue usage denial", Journal of International Marketing, 25(2), 52-71

Kotler, P., \& Gertner, D. (2002), "Country as brand, product, and beyond: A place marketing and brand management perspective", Journal of brand management, 9(4), 249-261.

Kotler, P., Jatusripitak, S., \& Maesincee, S. (2005), “Ulusların Pazarlanması (Ulusal Refahı Oluşturmada Stratejik Bir Yaklaşım), Çeviren: Ahmet Buğdaycı, Türkiye İş Bankası Kültür Yayınları, İstanbul.

Lu Wang, C., \& Xiong Chen, Z. (2004), "Consumer ethnocentrism and willingness to buy domestic products in a developing country setting: testing moderating effects", Journal of Consumer Marketing, 21(6), 391400 .

Magnusson, P., Westjohn, S.A. and Zdravkovic, S. (2011), "What? I thought Samsung was Japanese': accurate or not, perceived country of origin matters", International Marketing Review, 28 (5), 454-472.

Majid, K. (2017), “Drawing negative inferences from a positive country-of-origin image: consumers' use of COI and price levels to assess counterfeit drugs", International Marketing Review, 34 (2), 293-310.

Martin, O.M. and Cerviño, J. (2011), “Towards an integrative framework of brand country of origin recognition determinants: a cross-classified hierarchical model", International Marketing Review, 28 (6), 530-558. 
Paswan, A.K. and Sharma, D. (2004), "Brand-country of origin (COO) knowledge and COO image: investigation in an emerging franchise market", Journal of Product \& Brand Management, 13 (3), 144-155.

Pharr, J.M. (2005), "Synthesizing country-of-origin research from last decade: is the concept still salient in an era of global brands?", Journal of Marketing Theory and Practice, 13 (4), 34-45.

Rojas-Méndez, J. I., Murphy, S. A., \& Papadopoulos, N. (2013). The US brand personality: A Sino perspective. Journal of Business Research, 66(8), 1028-1034.

Samiee, S., Shimp, T.A. and Sharma, S. (2005), "Brand origin recognition accuracy: its antecedents and consumers' cognitive limitations", Journal of International Business Studies, 36 (4), 379-397.

Samiee, S. (2011), "Resolving the impasse regarding research on the origins of products and brands", International Marketing Review, 28 (5), 473-485.

Sharma, P. (2011), "Country of origin effects in developed and emerging markets: exploring the contrasting roles of materialism and value consciousness", Journal of International Business Studies, 42 (2), 285-306.

Thakor, M.V., Kohli, C.S. (1996), “Brand origin: conceptualization and review”, Journal of Consumer Marketing, 13 (3), 27-42.

Thakor, M.V., Lavack A.M. (2003), "Effect of perceived brand origin associations on consumer perceptions of quality", Journal of Product \& Brand Management, 12 (6), 394-407.

Usunier, J. C. (2006), "Relevance in business research: the case of country-of-origin research in marketing", European Management Review, 3 (1), 60-73.

Usunier, J.C. (2011), “The shift from manufacturing to brand origin: suggestions for improving COO relevance”, International Marketing Review, 28 (5), 486-496.

Wang, C. K., \& Lamb, C. W. (1983). “The impact of selected environmental forces upon consumers' willingness to buy foreign products", Journal of the Academy of marketing Science, 11(1-2), 71-84.

Zhuang, G., Wang, X., Zhou, L. and Zhou, N. (2008), "Asymmetric effects of brand origin confusion: evidence from the emerging market of China", International Marketing Review, 25 (4), 441-457.

\section{İnternet Kaynakları}

(2019) AEI Beyond 2030: Economic Growth in the Middle East and North Africa: https://www.aei.org/ publication/beyond-2030-economic-growth-in-the-middle-east-and-north-africa/

(2017). Ahram: http://english.ahram.org.eg/NewsContent/1/64/281848/Egypt/Politics-/A-young-nation—ofEgypts-population-are-under-.aspx

(2018). Aljazeera: https://www.aljazeera.com/news/2018/03/mbc-removes-turkish-tv-dramabroadcast-180.305.105648251.html

(2019). Beko PLC: https://www.bekoplc.com/news/uk-number-1-large-home-appliance-brand/

(2019). Brand Finance: https://brandirectory.com/rankings/automobiles-100-2019

(2019). Capital: https://www.capital.com.tr/sirket-panosu/sirket-panosu-haberleri/3-kenyali-bebekten-1i-molfixgiyecek

(2018). Dünya: https://www.dunya.com/kose-yazisi/turkler-gelecek-yil-misirda-endustri-bolgesi-kuracak/420530

(2018). Egypt Independent: https://ww.egyptindependent.com/egyptian-government-to-count-number-ofexpatriates/

(2018). Egypt Today: https://www.egypttoday.com/Article/3/50919/Analysis-What-are-Egyptians-using-theinternet-for

(2017). Ekonomist. https://www.ekonomist.com.tr/arastirmalar/misir-ile-ticaret-sessiz-sedasiz-buyuyor.html

(2012). Financial Times: https://www.ft.com/content/7585c3ee-3980-11e2-85d3-00144feabdc0

(2018). Hoot Suite: https://hootsuite.com/resources/digital-in-2018-emea 
(2018). Mubasher: https://english.mubasher.info/news/3274505/Car-sales-in-Egypt-grew-32-in-Q1-AMIC

(2019). Hurriyet Daily: http://www.hurriyetdailynews.com/ban-on-turkish-dramas-in-the-gulf-backfiresresearcher-140606

(2019). IKEA: https://www.ikea.com/jp/en/about_ikea/newsitem/20180128_Ingvar_Kamprad

(2019. Kültür Bakanlığı: http://www.kultur.gov.tr/Eklenti/63273,border-statistics-2018xlsx.xlsx?0

(2019). LCWaikiki: http://corporate.lcwaikiki.com/magazalar

(2019). MFA: http://www.mfa.gov.tr/-misir-ekonomisi.tr.mfa

(2019). Perakende.org: https://www.perakende.org/hayat-kimya-kenya-pazarinda-da-liderlik-hedefliyor134.281.2761h.html

(2019). Perakende.org: https://www.perakende.org/defacto-fas-bolgesinin-moda-oncusu-olmaya-aday134.281.3202h.html

(2019). Popcouncil: https://www.popcouncil.org/research/survey-of-young-people-in-egypt

(2019). Sabah: https://www.sabah.com.tr/yazarlar/kerem-alkin/2019/05/01/hedef-kg-basina-2-dolar

(2018). The Arab Weekly: https://thearabweekly.com/egypt-calls-grow-boycott-turkish-goods

(2018). The Conversation: http://theconversation.com/how-ikeas-founder-exported-a-certain-image-ofsweden-from-frugality-to-fika-91017

(2019). TİM İhracat 2019 Raporu: https://www.tim.org.tr/files/downloads/sunumlar/Y\%C3\%B6nlendirme\%20 Sunumlar\%C4\%B 1/Karisik/Yeni\%20Vizyon \%2 0 Yeni $\% 20$ Yol $\% 20$ Haritas $\%$ C 4\% B $1 \% 20$ \%C4\%B0hracat\%202019\%20Raporu.pdf

(2018). TİM Misır Ülke Bilgi Notu: İstanbul: Türkiye İhracatçllar Meclisi. http://www.tim.org.tr/files/downloads/ ihracat/Ulke_Masalari/ulke_bilgi_notu/Misir_Bilgi_Notu.pdf

(2019). TOBB: https://tobb.org.tr/Sayfalar/Detay.php?rid=22620\&lst=MansetListesi

(2019). The World Fact: https://www.cia.gov/library/publications/the-world-factbook/geos/eg.html

(2019) Worldometers: https://www.worldometers.info/world-population/egypt-population 